\title{
A Game Model of Air Pollution Control from Vessels in and around Ports
}

\section{Qin Wang ${ }^{1,2, a}$, Laijun Zhao ${ }^{2, b,}$, Lijun Zeng ${ }^{3, c}$ and Qiang Zhang ${ }^{1, d}$}

\author{
${ }^{1}$ School of Transport \& Communications, Shanghai Maritime University, Shanghai, China; \\ 2 Sino-US Global Logistics Institute, Shanghai Jiaotong University, Shanghai, China \\ ${ }^{3}$ College of Economics and Management, Shandong University of Science and Technology, \\ Qingdao, China
}

aquinwang@shmtu.edu.cn, bljzhao70@sjtu.edu.cn, cljzsjy@sjtu.edu.cn, dqiangzhang@shmtu.edu.cn

${ }^{*}$ Corresponding author

Keywords: Air pollution from vessels, Cooperation, Game theory, Emission tax.

\begin{abstract}
Air pollution from vessels has been greatly concerned. Pollutants discharged by those vessels severely reduces the quality of air, affects the health of residents, and jeopardizes the balance of ecosystem in and around ports. Firstly, a game model of air pollution control from vessels was constructed. Then the paper quantitatively analyzes the necessity of cooperation between Shanghai Port and Ningbo-Zhoushan Port. Finally, the paper was concluded with some suggestions on the prevention of pollution from vessels in and around the two ports. This study contributes to making China's air pollution reduction targets come true, improving the air quality of port cities and alleviating health problems caused by air pollution.
\end{abstract}

\section{港口船舶大气污染治理的博弯分析 \\ 王芹 $1,2, \mathrm{a}$, 赵来军 $2, \mathrm{~b},{ }^{*}$, 曾丽君 ${ }^{3, c}$, 章强 $1, \mathrm{~d}$ \\ 1 交通运输学院, 上海海事大学, 上海, 中国 \\ 2 中美物流研究院, 上海交通大学, 上海, 中国 \\ ${ }^{3}$ 经济管理学院, 山东科技大学, 青岛, 中国}

aqinwang@shmtu.edu.cn, bljzhao70@sjtu.edu.cn, Cljzsjy@sjtu.edu.cn, dqiangzhang@shmtu.edu.cn “通讯作者

关键词: 船舶大气污染;博弯论; 排放税

中文摘要. 船舶大气污染一直备受关注，船舶排放的大气污染物对港口城市空气质量、居民 健康和生态环境影响十分严重。论文首先建立港口船舶大气污染治理博弯模型, 然后定量分 析上海港和宁波一舟山港合作治理船舶大气污染的必要性。最后, 给出两港治理船舶大气污 染的相关建议。研究结论为我国实现大气污染减排目标、改善港口城市空气质量、减缓大气 污染健康损害提供新思路。

\section{1. 引言}

近年来交通运输部、海事局、各级港口环保部对船舶大气污染防治问题非常重视，相继 颁布/修订法案对过境船舶产生的空气污染物进行防治。2016 年, 交通运输部海事局发布 《关于规范船舶大气污染防治监督管理工作的通知》，强调加强 “船舶大气污染监管工 
作”。2017年，交通运输部发布《关于推进长江经济带绿色航运发展的指导意见》，强调 “组织船舶污染防治专项治理”。

征收排污税在治理船舶大气污染方面具有较强激励作用。1990 年, 芬兰征收SOx排放税 （\$1.45/t），随后荷兰等21 国开始效仿。Carr 和Corbett（2015）指出对符合IMO排放标准的 过境船舶征收较少通行税（\$4.06/桶），对违规排放船舶征收较高排污税，能够减少船舶大 气污染物排放量。Tseng 和Pilcher (2016) 指出征收排污税能够降低船舶大气污染物排放 量, 但在实践中还面临着较多阻力。Devanney 和Beach (2011) 认为直接对船用燃油征税更 为简单有效, 对超标排放的船东应当进行处罚（拒绝靠港、扣留船舶、拍卖船舶等）。Zhao 等（2014）指出京津翼各省合作治理大气污染，能够有效减少治污成本。

本文首先运用博弯论建立两个港口船舶大气污染治理的博弯模型。然后，运用 MATLAB 软件对港口吞吐量与污染物排放量进行拟合, 定量分析征收船舶大气污染物排放 税背景下港口合作与不合作治理船舶大气污染获取的收益问题。最后, 给出港口减少船舶大 气污染物排放的政策建议。

\section{2. 港口船舶大气污染治理博弃模型}

港口企业是独立的理性决策者, 通过调整自身吞吐量实现收益最大化。模型参数见表 1 。

表 1 港口船舶大气污染博弯模型参数

\begin{tabular}{|c|c|c|}
\hline 参数 & 含义 & 单位 \\
\hline$a$ & 每个集装箱的最大服务价格 & 元 \\
\hline$c_{i}$ & 港口 $\mathrm{i}$ 每个集装箱的边际服务成本 & 元 \\
\hline$\beta$ & 船舶空载时污染物产生量 & 吨 \\
\hline$\alpha$ & 每 TEU 污染物产生量 & 吨/标准箱 \\
\hline $\mathrm{t}$ & 污染物排放税 & 元/吨 \\
\hline$p_{i}$ & $\mathrm{i}$ 港口的集装箱服务价格 & 元/标准箱 \\
\hline$b$ & 价格参数 & 元/万标准箱 \\
\hline$e_{i}$ & $\mathrm{i}$ 港口的污染物排放量 & 吨 \\
\hline
\end{tabular}

根据古诺博亦模型, $i$ 港口集装箱服务的逆需求函数为 $p_{1}=a-q_{1}-b q_{2}, p_{2}=a-q_{2}-b q_{1}$, 其中 $b>0$ 。船舶排放的污染物总量 $e_{i}$ 与港口吞吐量 $q_{i}$ 密切相关, $i$ 港口污染物产生量函数为 $e_{i}=\alpha q_{i}+\beta$ 。 $i$ 港口的收益为:

$$
R_{i}=\left(p_{i}-c_{i}\right) q_{i}-t e_{i}
$$

\section{1 港口船船大气污染治理的非合作博弯分析}

假设港口企业独立做出决策，根据最优化理论，有

$$
\frac{\partial R_{i}}{\partial q_{i}}=a-c_{i}-b q_{j}-2 q_{i}-\alpha t
$$

又因为 $\frac{\partial^{2} R_{i}}{\partial q_{i}{ }^{2}}=-2<0$, 且最大值点在一阶导数等于零处取得。假设均衡点为 $\left(q_{1}^{*}, q_{2}{ }^{*}\right)$, 则 $q_{1}^{*}=\frac{a-c_{1}-\alpha t}{b+2}+\frac{b\left(c_{2}-c_{1}\right)}{4-b^{2}}, q_{2}{ }^{*}=\frac{a-c_{1}-\alpha t}{b+2}-\frac{2\left(c_{2}-c_{1}\right)}{4-b^{2}}$ 。因此, $\left(q_{1}{ }^{*}, q_{2}{ }^{*}\right)$ 是唯一的纳什均衡点。

\section{2 港口船舶大气污染治理的合作博弯分析}


某段时期内, 区域内港口吞吐量相对稳定, 假设 $Q=q_{1}+q_{2}$ 。此时, 如果两个集装箱港口 建立联盟统一集装箱服务价格 $p$, 由逆需求函数可得 $p(Q)=a-\frac{(b+1)}{2} Q$ 。两个集装箱港口的 总收益 $R_{\text {合 }}$ 为

$$
R_{\text {合 }}=p(Q) Q-c Q-t\left(e_{1}+e_{2}\right)=(a-c) Q-\frac{b+1}{2} Q^{2}-\alpha t Q-2 t \beta
$$

又因为 $\frac{\partial R_{\text {合 }}}{\partial Q}=a-c-(b+1) Q-\alpha t, \frac{\partial^{2} R_{\text {合 }}}{\partial Q^{2}}=-(b+1)<0$, 可知使得两集装箱港口总利润最大的总吞 吐量 $Q_{\text {合 }}$ 为 $Q_{\text {合 }}=\frac{a-c-\alpha t}{b+1}$ 。易知,

$$
q_{1}^{*}+q_{2}^{*}=\frac{2(a-c-\alpha t)}{b+2}, \quad\left(R_{1}+R_{2}\right)-R_{\text {合 }}=(b-1) \frac{\left(q_{1}^{*}-q_{2}^{*}\right)^{2}}{2}<0 .
$$

可得

$$
Q^{*}=q_{1}^{*}+q_{2}^{*}>Q_{\text {合 }}, R_{1}+R_{2}<R_{\text {合}} .
$$

说明港口企业在应对环保部征收船舶大气污染物排放税时, 两个集装箱港口合作建立联盟, 比不合作时能够以较少的总吞吐量获得更多的总收益, 即合作减排比自由竞争更具优势, 港 口收益更多。

\section{3. 数值实验}

本节进行模拟仿真以检验港口合作治理大气污染的合作效果。首先, 基于现有的船舶大 气污染物排放清单（Yin et al.,2017），获取 2010 年珠三角、深圳市、宁波舟山港、洋山港 以及 2012 年天津港、大连港的集装箱吞吐量和 $\mathrm{PM}_{2.5}$ 排放量, 运用 MATLAB 进行数据拟合, 可得 $\alpha=0.6147, \beta=633$ 。 $R^{2}=0.7977>0.7$, 表明相关关系显著, 拟合效果较好。

选取上海港和宁波一舟山港为例，假设港口 1 为上海港，港口 2 为宁波一舟山港，以 20 英尺普通重箱和 $\mathrm{PM}_{2.5}$ 为例。参考上港集团和宁波舟山港股份有限公司的港口作业包干费收 费标准, 参数取值分别设置为 $a=3000$ 元, $b=0.2$ 元/万标准箱, $c_{1}=c_{2}=1500$ 元, $t=100$ 元 $/$ 吨, 可得 $q_{1}=\mathrm{q}_{2} \approx 654$ 万标准箱, $R_{1}=R_{2} \approx 364,239$ 元, $R_{1}+R_{2}<R_{\text {合 }}=735,636$ 。可以看出, 上海 港和宁波一舟山港合作应对政府征收船舶大气污染物排放税相比不合作能够获取更多的收 益。

\section{4. 结论}

本文运用古诺博恋理论构建了两个港口船舶大气污染治理博恋模型, 分析了征收环保税 背景下港口合作与不合作港口总收益的变化情况。研究表明, 相比独立治污, 港口合作能够 获取更高的总收益。相关部门可以通过加强监管和完善船舶大气污染物排放税征收方案减少 过境船舶的空气污染物排放量。

\section{致谢}

本文是第 62 批中国博士后基金项目（No. 2017M621490）、上海市浦江人才计划 （No.14PJC060）和上海市软科学项目（No.17692104900）阶段成果之一。 


\section{References}

[1] E W Carr, J J Corbett. Ship compliance in emission control areas: technology costs and policy instruments[J]. Environmental Science \& Technology, vol.49, pp. 9584-9591, 2015.

[2] H Cui, T Notteboom. Modelling emission control taxes in port areas and port privatization levels in port competition and co-operation subgames, Transportation Research Part D, vol 56, pp.110-128,2017.

[3] J Devanney, S Beach.Direct taxation of ship-based $\mathrm{CO}_{2}$ emissions[J]. Florida, 2011.

[4] P H Tseng, N Pilcher. Exploring the viability of an emission tax policy for ships at berth in Taiwanese ports[J]. International Journal of Shipping and Transport Logistics, vol.8, pp. 705$722,2016$.

[5] P L Yin, Z C Huang, D N Zheng et al. Marine vessel emission and its temporal and spatial distribution characteristics in Ningbo - Zhoushan Port, China Environmental Science, vol 37, pp.27-37,2017.

[6] L Zhao, J Xue, H Gao, et al. A model for interprovincial air pollution control based on futures prices[J], Journal of the Air \& Waste Management Association, vol.64, pp. 552-560, 2014. 